\title{
The Onset of Acne Vulgaris among Adult Women and the Effectiveness of Therapy with Ferulic Acid and D`arsonwal's Currents
}

\author{
Izabela Zaleska*1 and Anna Kamm ${ }^{2}$ \\ ${ }^{1}$ The Section of Professional Cosmetology, The Faculty of Motor Rehabilitation, University of Physical Education in Krakow, Poland \\ ${ }^{2}$ The Department of Medical Chemistry of Medical University of Gdańsk, Poland
}

Received: 阱 August 08, 2018; Published: 海 August 13, 2018

*Corresponding author: Izabela Zaleska, The Section of Professional Cosmetology, The Faculty of Motor Rehabilitation, University of Physical Education in Krakow, Poland

Abstract

Introduction: Acne vulgaris as a skin disease does not only affect young people. It is extremely acute and more common problem among adults, that appears around the age of 25 or lasts continuously from the time of maturity. Unaesthetic appearance especially for women may be a reason of discomfort, depression and in serious cases it may lead to suicide attempts.

Purpose: the study aims at presenting the change in the number of inflammatory and non-inflammatory exanthema, before and after a series of treatments with the use of Ferulic acid applied manually and d'Arsonowal currents on adult women suffering from acne vulgaris continuously from puberty and after the age of 25 .

Materials and Methods: The study was conducted on 60 women over the age of 25. The criterion of inclusion was existing number of inflammatory and non-inflammatory exanthema. They were randomly divided into two groups. The probands were asked to fill in the survey and were informed about the possible contraindications for conducted treatments. The first group probands were applied manually with Ferulic acid on cleansed skin over the period of 10 minutes. The second group probands were applied with d'Arsonowal currents' emission on dry and cleansed skin for a period of 10 minutes. The procedure in both groups was applied in a series of 5 treatments with one week break. The number of exanthema was documented photographically for each proband before the first and after the last procedure.

Results: The results of research show statistically essential decrease in the number of inflammatory and non-inflammatory exanthema in both groups- treated with Ferulic acid and treated with d'Arsonowal currents. No differences concerning the number and kind of exanthema between tested groups before a series of treatments and after a series of treatments were noted. Researching the correlation of number of inflammatory and non-inflammatory exanthema to the moment of illness emergence and applied procedure does not show statistically essential differences either.

Conclusion: Regardless, the progress of an illness among the probands and what kind of exanthema was dominating, the support of treatments working externally on skin such as emission of d'Arsonowal currents and application of Ferulic acid effectively and successfully improve the condition of acne affected skin. Especially in situations when a patient cannot use pharmacological treatment for any reason, the external treatments might work as an alternative or a supplement.

Keywords: Acne Vulgaris; Acne Tarda; D`Arsonwal’s Currents; Ferulic acid

\section{Introduction}

Acne vulgaris is a quite common illness of hair follicles and sebaceous glands, primarily located on the face area (forehead, chin nose, cheeks) but also chest and back. Typically, such an affliction is chronic and recurring. In its acute stage, it can lead to lasting and often enough extremely disfiguring scars. Their visible location is usually an additional emotional burden for the people inflicted with this disease and it definitely lowers their quality of life. For a long time, Acne vulgaris was identified only with the period of puberty. In 1964, Loughlin's research revealed, that the illness can emerge also in the adulthood. In that age group, because of the occurrence time of the disease, two types can be distinguished: a) puberty continuation - persistent acne,

b) symptoms, whose beginning is noticed around the age of 25- late onset acne [1].

In a subject literature, information can also be found about reoccurring acne among adult women. The researchers' descriptions inform that it disappears after puberty in order to reactivate in the period of adulthood [2]. The most characteristic skin changes that accompany the illness are blackheads and whiteheads, more seldom papules and pustules [3]. 
The pathogenesis of acne among adult women covers most of all, excessive sebum production, disorder of follicular xeroderma and comedo formation in hair follicles and colonization of the follicle by Propionibacterium acnes and inflammatory stage [4]. The research proved a significant role of other factors that influence the skin condition with acne changes, such as genetic predisposition, hormonal changes, long-lasting stress, diet with high glycemic index, comedogenic cosmetics and smoking cigarettes [5]. Ferulic acid is plant originated, it is very often encountered in fruit and vegetables such as tomatoes, corn, rice bran and wheat grain. It is the effective sweeper of free radicals and it was approved in some countries as a food additive in order to prevent lipid peroxidation. Ferulic acid consumed by people is metabolised and excreted. The high concentration of the acid remains in blood definitely longer then other antioxidants such as Vitamin C [6]. The researchers successfully point out its anti-oxidative, anti-inflammatory, neuroprotective and anti-proliferative activity [7]. Positive influence of exposition of human organism to electricity has been used by scientists for many years.

The human body has the perfect abilities to work as an electric conductor [8]. D`Arsonwal's currents are qualified as high frequency currents, with wave length of 1000-600 m and frequency of 300$500 \mathrm{kHz}$. D'Arsonvalization is used in seborrhoeic skin treatment with tendency towards acne vulgaris [9]. As a result of electrostatic discharges of high frequency currents, ozone is produced, which is one of the strongest antioxidants.It also possesses very high bactericidal, fungicidal and virucidal properties, which is connected with its high oxidoreductive potential, destroying enzyme structures of microorganisms. The crucial part is that this destructive property on anaerobic bacteria, that are one of the reasons of deterioration of acne infected skin [10].

\section{The Purpose of Work}

The purpose of the following work it to evaluate the treatment procedures based on Ferulic acid application and d'Arsonwal's high frequency currents in the context of reduction of exanthema in inflammatory and non-inflammatory stage among adult women, when the onset appeared in adulthood and lasts continuously from puberty.

\section{Methods and Materials}

The research was carried out on a group of 60 women. The patients were randomly divided into 2 groups. In both- the first and the second group, the criteria for exclusion were: pregnancy, the period of breastfeeding, violation of continuity of epidermis, acute or chronic infections, acne rosacea, atopic skin or skin with seborrhoeic dermatitis, undergoing surgical procedures within the last 6 months and around face area, using retinoids up to six months back, metal implants or simulators. The inclusion criteria were: sex- woman and the right type of skin- problematic with changes characteristic for acne acne vulgaris. The first group of probands were applied Ferulic acid with manual method. Second group probands were applied d'Arsonwal's high frequency currents by using contact method.
The treatment was conducted in series of 5 treatments with a one week break. Before and after the series of treatments, the effectiveness of therapy was evaluated by counting the number of exanthema with their division into inflammatory and noninflammatory. Photographic evidence was produced. All the probands voluntarily gave permission to participate in the discussed study. Each of the probands was informed, about the purpose of research, duration time and the way of its realising, anticipated advantages, potential risks and dangers, all inconveniences connected with taking part in the study and also rights and obligations. Additional questions that might have appeared while treatment process, could be asked directly by the probands to the person conducting the treatment. The study was conducted with the agreement of Independent Bioethics Commission for Research at Medical University of Gdańsk.

\section{Statistical Methodology}

All the calculations were conducted by using statistical software StatSoft. Inc. (2014). STATISTICA (data analysis software system), version 12.0. www.statsoft.com and Excel spreadsheet. Quantitative variables were characterized by using Arithmetic mean, standard deviation, Median, minimum and maximum value (scope), and 95\%CI (confidence interval). On the other hand, qualitative variables were represented by using numerousness and proportion value (percentage). In order to control if quantitative variable was a result of population with normal distribution, W. Shapiro-Wilk test was used. However, to control the hypothesis regarding equal variants, Leven (Brown-Forsythe) test was applied. The gravity of differences between two groups (the model of unrelated variables) was tested by using the significance of differences test: student's t-test, (or in case of lack of homogeneity of variants -Welch test) or Mann-Whitney $U$ test (in case of non-compliance of conditions of applying student's t-test or variables measured on ordinal scale).

The significance of differences between more than two groups was checked by using F test (ANOVA) or Kruskal-Wallis test (in case of non-compliance of conditions of applying ANOVA).

In case of receiving significant statistic differences between the groups, post hoc analysis was applied (for F test - Tukey test, for Kruskal-Wallis- Dunn test). In case of two variables interrelated model, student's t-test was applied or Wilcoxon signed-rank test (in case of non-compliance the conditions of applying student's t-test or for variables measurements on ordinal scale). The significance of differences between more than two variables interrelated model was checked by using variants analysis with repeated measurements or Friedman test (in case of non-compliance of conditions of applying the variants analysis with repeated measurements or for variables measured on ordinal scale).Tests of independence A chisquared test, were used for qualitative variables (adequately with the use of correction according to Yates for the numerousness of cells below 10, checking Cochran's conditions and precise Fisher test). In order to find connection, force and direction between variables, correlation analysis was used, by calculating Pearson or/ and Spearman correlation coefficient. In all calculations the level of gravity was acknowledged at $\mathrm{p}=0.05$. 


\section{Results}

\section{Age and the Time of Illness}

In the proband group that was applied Ferulic acid, the average age is $30,8(4,8)$ range $24-42$ years), and in the group with D 'Arsonwal's currents applied, the average age is 30,3 (4,9) (range 23-42 years). No significant statistic differences regarding the age of probands in the compared groups were stated $(p=0,7303)$. In the proband group that was applied with Ferulic acid, $50.0 \%$ of probands marked the time of acne appearance in puberty, and in the D`Arsonwal's currents group the number was 46,7\%. No significant statistic differences regarding the time when acne appeared in the compared groups were stated ( $p=0,7961)$.The detailed information was shown in Table 1 . The correlation of number of inflammatory exanthema in relation to the onset of illness

Table 1: Characteristics of researched groups regarding the age and acne onset.

\begin{tabular}{|c|c|c|c|c|}
\hline & $\begin{array}{c}\text { Ferulic acid } \\
(\mathbf{N}=\mathbf{3 0})\end{array}$ & $\begin{array}{c}\text { D`Arsonwal } \\
\mathbf{( N = 3 0 )}\end{array}$ & $\begin{array}{c}\text { In total } \\
\mathbf{( N = 6 0 )}\end{array}$ & value p \\
\hline \multicolumn{5}{|c|}{ Wiek } \\
\hline $\begin{array}{c}\text { average } \\
\text { (SD) }\end{array}$ & $30,8(4,8)$ & $30,3(4,9)$ & $30,6(4,8)$ & ${ }^{1} 0,7303$ \\
\hline Scope & $24,0-42,0$ & $23,0-42,0$ & $23,0-42,0$ & \\
\hline Median & 30,0 & 30,0 & 30,0 & \\
\hline 95\%CI & {$[29,0 ; 32,6]$} & {$[28,5 ; 32,2]$} & {$[29,3 ; 31,8]$} & \\
\hline \multicolumn{5}{|c|}{ Time of acne onset } \\
\hline Puberty & $15(50,0 \%)$ & $14(46,7 \%)$ & $29(48,3 \%)$ & ${ }^{2} 0,7961$ \\
\hline maturity & $15(50,0 \%)$ & $16(53,3 \%)$ & $31(51,7 \%)$ & \\
\hline
\end{tabular}

Note: ${ }^{1}$ t-Student $(0,35) ;{ }^{2}$ Chi2 $(0,07)$.

\section{The Beginning of An Illness In Puberty- Inflammatory Exanthema}

Table 2: Characteristics of researched groups regarding the number of inflammatory exanthema before the first treatment and after the fifth treatment for probands who suffered from acne in the time of puberty.

\begin{tabular}{|c|c|c|c|}
\hline & $\begin{array}{c}\text { Ferulic acid } \\
(\mathbf{N}=\mathbf{3 0})\end{array}$ & $\begin{array}{c}\text { D`Arsonwal } \\
(\mathbf{N}=30)\end{array}$ & Value p \\
\hline \multicolumn{4}{|c|}{ Before $\mathbf{1}^{\text {st }}$ treatment } \\
\hline average (SD) & $4,6(4,8)$ & $8,1(6,1)$ & \\
\hline Scope & $0,0-13,0$ & $1,0-22,0$ & \\
\hline median & 3,0 & 7,0 & ${ }^{1} 0,0887$ \\
\hline 95\%CI & {$[1,9 ; 7,3]$} & {$[4,5 ; 11,6]$} & \\
\hline \multicolumn{4}{|c|}{ Afer $\mathbf{5}^{\text {th }}$ treatment } \\
\hline average (SD) & $1,1(2,0)$ & $0,6(1,4)$ & \\
\hline Scope & $0,0-5,0$ & $0,0-4,0$ & \\
\hline median & 0,0 & 0,0 & ${ }^{2} 0,7270$ \\
\hline 95\%CI & {$[0,0 ; 2,2]$} & {$[-0,2 ; 1,5]$} & \\
\hline Value p & ${ }^{3} 0,0033$ & ${ }^{4} 0,0002$ & \\
\hline
\end{tabular}

Note: ${ }^{1}$ Mann-Whitney $(-1,70) ;{ }^{2}$ Mann-Whitney $(0,35) ;{ }^{3}$ Wilcoxon $(2,93) ;{ }^{4}$ t-Student $(5,16)$.

No significant statistical changes before the first treatment in the number of inflammatory exanthema was noticed depending on the kind of treatment for probands with acne in puberty ( $\mathrm{p}=0,0887)$. No significant statistical changes after the fifth treatment in the number of inflammatory exanthema was noticed depending on the kind of treatment for probands with acne in puberty $(p=0,7270)$. With the probands who suffered form acne in the period puberty, in the Ferulic acid group, the number of inflammatory exanthema after the fifth treatment was significantly lowered $(p=0,0033)$. In the D`Arsonwal's currents group with the probands who suffered from acne in puberty, the number of inflammatory exanthema after the fifth treatment was also significantly lowered $(p=0,0002)$. The detailed data was shown in Table 2 .

\section{The Onset of Ilness in Maturity - Inflammatory Exanthe-} ma

Before the first treatment the number of inflammatory exanthema in the D'Arsonwal's currents group was significantly higher for probands who suffered from acne in maturity ( $p=0,0438$ ). No significant statistical changes after the fifth treatment in the number of inflammatory exanthema was noticed depending on the kind of treatment for probands with acne in maturity $(p=0,7518)$. In the group of probands who suffered from acne in maturity, after the fifth treatment with Ferulic acid, the number of inflammatory exanthema was significantly lower $(p=0,0160)$. In the group of probands who suffered from acne in maturity, after the fifth treatment with D'Arsonwal's currents, the number of inflammatory exanthema was significantly lower $(\mathrm{p}=0,0001)$. The detailed data was shown in Table 3.

Table 3: Characteristics of researched groups regarding the number of inflammatory exanthema before the first treatment and after the fifth treatment for probands who suffered from acne in the time of maturity.

\begin{tabular}{|c|c|c|c|}
\hline & $\begin{array}{c}\text { Ferulic acid } \\
(\mathbf{N}=30)\end{array}$ & $\begin{array}{c}\text { D`Arsonwal } \\
(\mathbf{N}=30)\end{array}$ & value p \\
\hline \multicolumn{4}{|c|}{ Before $\mathbf{1}^{\text {st }}$ treatment } \\
\hline average (SD) & $3,1(3,8)$ & $6,1(3,9)$ & \\
\hline Scope & $0,0-12,0$ & $0,0-11,0$ & \\
\hline median & 1,0 & 7,0 & ${ }^{1} 0,0438$ \\
\hline 95\%CI & {$[1,0 ; 5,2]$} & {$[4,0 ; 8,1]$} & \\
\hline \multicolumn{4}{|c|}{ After $\mathbf{5}^{\text {th }}$ treatment } \\
\hline average (SD) & $1,5(2,3)$ & $0,9(1,7)$ & \\
\hline Scope & $0,0-6,0$ & $0,0-6,0$ & \\
\hline median & 0,0 & 0,0 & ${ }^{2} 0,7518$ \\
\hline 95\%CI & {$[0,2 ; 2,7]$} & {$[0,0 ; 1,8]$} & \\
\hline Value p & 30,0160 & 40,0001 & \\
\hline
\end{tabular}

Note: ${ }^{1}$ Mann-Whitney $(-2,02) ;{ }^{2}$ Mann-Whitney $(0,32) ;{ }^{3}$ t-Student $(2,74) ;{ }^{4}$-Student $(6,12)$.

\section{The Correlation of Number of Non-Inflammatory Exanthema In Relation To The Onset of Illness .The Beginning of an Illness In Puberty-Non- Inflammatory Exanthema}

No significant statistical changes before the first treatment in the number of non-inflammatory exanthema was noticed depending on the kind of treatment for probands with acne in 
puberty $(p=0,7578)$. No significant statistical changes after the fifth treatment in the number of non-inflammatory exanthema was noticed depending on the kind of treatment for probands with acne in puberty $(p=0,9652)$. In the group of probands who suffered from acne already in puberty, after the fifth treatment with Ferulic acid, the number of non-inflammatory exanthema was significantly lower $(p=0,0010)$. In the group of probands who suffered from acne already in puberty, after the fifth treatment with D`Arsonwal's currents, the number of non-inflammatory exanthema was significantly lower $(\mathrm{p}=0,0007)$. The detailed data was shown in Table 4.

Table 4: Characteristics of researched groups regarding the number of non-nflammatory exanthema before the first treatment and after the fifth treatment for probands who suffered from acne in the time of puberty.

\begin{tabular}{|c|c|c|c|}
\hline & $\begin{array}{c}\text { Ferulic acid } \\
(\mathbf{N}=30)\end{array}$ & $\begin{array}{c}\text { D'Arsonwal } \\
(\mathbf{N}=30)\end{array}$ & value p \\
\hline \multicolumn{4}{|c|}{ Before $1^{\text {st }}$ treatment } \\
\hline average (SD) & $12,8(9,4)$ & $11,8(8,0)$ & \\
\hline Scope & $0,0-37,0$ & $2,0-25,0$ & \\
\hline median & 10,0 & 10,5 & ${ }^{1} 0,7578$ \\
\hline 95\%CI & {$[7,6 ; 18,0]$} & {$[7,2 ; 16,4]$} & \\
\hline \multicolumn{4}{|c|}{ After $5^{\text {th }}$ treatment } \\
\hline average (SD) & $6,4(7,1)$ & $5,1(4,0)$ & \\
\hline Scope & $0,0-26,0$ & $0,0-16,0$ & \\
\hline median & 5,0 & 4,0 & ${ }^{2} 0,9652$ \\
\hline 95\%CI & {$[2,5 ; 10,3]$} & {$[2,9 ; 7,4]$} & \\
\hline value p & ${ }^{3} 0,0010$ & ${ }^{4} 0,0007$ & \\
\hline
\end{tabular}

Note: ${ }^{1}$ t-Student $(0,31) ;{ }^{2}$ Mann-Whitney $(0,04) ;{ }^{3}$ t-Student $(4,17)$; ${ }^{4}$ t-Student $(4,41)$.

\section{The Onset of Illness In Maturity -Non-Inflammatory Exanthema}

Table 5: Characteristics of researched groups regarding the number of non-inflammatory exanthema before the first treatment and after the fifth treatment for probands who suffered from acne in the time of maturity.

\begin{tabular}{|c|c|c|c|}
\hline & $\begin{array}{c}\text { Ferulic acid } \\
(\mathbf{N}=\mathbf{3 0})\end{array}$ & $\begin{array}{c}\text { D`Arsonwal } \\
\mathbf{( N = 3 0 )}\end{array}$ & Value p \\
\hline \multicolumn{4}{|c|}{ Before $\mathbf{1}^{\text {st }}$ treatment } \\
\hline average (SD) & $11,9(7,8)$ & $10,9(6,2)$ & \\
\hline Scope & $0,0-25,0$ & $2,0-24,0$ & \\
\hline median & 12,0 & 9,5 & ${ }^{1} 0,0371$ \\
\hline $95 \% \mathrm{CI}$ & {$[7,6 ; 16,3]$} & {$[7,5 ; 14,2]$} & \\
\hline \multicolumn{4}{|c|}{ After $\mathbf{5}^{\text {th }}$ treatment } \\
\hline average (SD) & $3,7(4,7)$ & $6,0(4,4)$ & \\
\hline Scope & $0,0-18,0$ & $2,0-14,0$ & \\
\hline median & 2,0 & 3,5 & ${ }^{2} 0,0721$ \\
\hline 95\%CI & {$[1,1 ; 6,3]$} & {$[3,7 ; 8,3]$} & \\
\hline value p & ${ }^{3} 0,0001$ & ${ }^{4} 0,0004$ & \\
\hline
\end{tabular}

Note: ${ }^{1} \mathrm{t}-$ Student $(-2,19) ;{ }^{2}$ Mann-Whitney $(-1,80) ;{ }^{3}$ t-Student $(5,53)$; ${ }^{4}$ t-Student $(4,53)$.
Before the first treatment the number of non-inflammatory exanthema in the Ferulic acid group was significantly higher for probands who suffered from acne in maturity ( $p=0,0371)$. No significant statistical changes after the fifth treatment in the number of non-inflammatory exanthema was noticed depending on the kind of treatment for probands with acne in maturity $(p=0,0721)$. In the group of probands who suffered from acne in maturity, after the fifth treatment with Ferulic acid, the number of non-inflammatory exanthema was significantly lower $(p=0,0001)$. In the group of probands who suffered from acne in maturity, after the fifth treatment with D`Arsonwal's currents, the number of inflammatory exanthema was significantly lower $(p=0,0004)$. The detailed data was shown in Table 5.

\section{Discussion}

In both analysed groups, the average age of probands was determined at 30.6 which is compatible with range limits suggested by researchers. Szepietowski and Dreno, taking into account the achieved results, define the exanthema that appear after the age of 25 as adult acne [11,12]. The personal research showed the average age of probands at 30,8 with Ferulic acid group and 30,3 with D`Arsonwal's currents group. One of the characteristic features of acne vulgaris progress is the appearance of increased number of free radicals [13]. UV radiation absorption by Ferulic acid on skin stops the production of reactive forms of oxygen that is confirmed by study of Saij with the use of Spectrophotometry and Monti study. They point out protective activity of Ferulic acid against UV radiation $[14,15]$. The added value, during application of formulations containing Ferulic acid, is the possibility of application no matter the season of the year or the degree of insolation. That is possible, because the discussed acid is a natural sunscreen filter that practically does not cause any irritation. Thanks to that fact, therapeutic processes can be extended and the operation of other active substances can be strengthened [16]. One can therefore venture a statement that introduction of the discussed acid in formulations used in acne vulgaris therapy is justified.

D'Arsonowal currents belong to a group of high frequency currents. Their effect generates electric field in human tissues that corresponds with the frequency of these currents. In the near vicinity of condenser electrodes that emit currents, ozone is produced [17]. The ozone can be potentially dangerous for human beings, just because it significantly increases the risk of damaging skin cells. However, in controlled dosage the discussed gas becomes a perfect antiseptic resource, that supports healing processes of skin infections [18]. The highest attention is paid to ozone's antibacterial properties, that is produced while treatments with the use of high frequency currents. The excessive colonisation of anaerobic bacteria Propionibacterium acnes is often mentioned as one of the main reasons of acne vulgaris. Lynch and Swift confirmed, with their work, the elimination of bacteria by using ozone in a gas form. This fact seems to be highly useful $n$ the context of feasibility of application of the discussed gas on the skin surface in this exact state [19].

In both groups, treated with Ferulic acid and D`Arsonwal's currents there were probands, who stated the onset of illness for 
puberty and maturity. Even though, the probands were assigned to particular groups randomly, the number of afflicted since puberty was $48.3 \%$ in relation to the number of afflicted in the age of above 25 , which was $51.7 \%$. That shows that more than half of probands were suffering both before puberty and in the period of maturity. Perhaps, the increased number of probands would show greater quantitative differences in the future. Also Dreno in his studies underlines two kinds of adult acne vulgaris depending on the moment of its appearance: maturity and puberty. Because of slower and weaker reaction of older skin to treatments, Dreno advises to take on other methods of treatment regarding younger skin.

Personal research shows a statistically significant change in the number of inflammatory and non-inflammatory exanthema after the application of a series of treatments with the use of Ferulic acid, no matter the time of illness appearance. The time when patients were afflicted with acne does not seriously influence the treatment method.

One can notice, however the differences in reaction of particular exanthema in two groups. When comparing the number of inflammatory exanthema between the groups, no statistical differences were noticed, a bigger reduction is however clearly visible after the treatment with d'Arsonowal currents. The reaction of non-inflammatory exanthema is definitely better to Ferulic acid, when after application the reduction in greater numbers occurs. The effectiveness of Ferulic acid, makes it in this case, an attractive and safe healing alternative for acne with non-inflammatory exanthema. Personal research shows a statistically significant change in the number of exanthema- mainly inflammatory but also non-inflammatory after the application of a series of treatments with the use of high frequency currents despite the moment of appearance of illness for probands. Such a fact confirms the concept of using of d'Arsonowal currents as a method of combating anaerobic bacteria, involved in pathogenesis of acne vulgaris. The greatest reduction of inflammatory exanthema was observed just after the fifth and final treatment. It especially regarded people that were applied with d'Arsonowal currents that produced ozone. A higher effectiveness in the reduction of non-inflammatory exanthema was by contrast achieved after a series of treatments with the use of formulation enriched with Ferulic acid.

\section{Summary}

The research over the influence of Ferulic acid and d'Arsonowal currents over the number of inflammatory and non-inflammatory exanthema among adult women with diagnosed acne vulgaris, proved the decrease in the number of exanthema no matter the probands' onset of an illness. The results gained, demonstrate that both methods applied on the surface of the skin may be used interchangeably in a mild stage of acne and they can support pharmacological treatment with more severe stages of acne. Regardless of the time when an adult woman developed the illnessif it happened after the age of 25 or from the time of puberty.

Because of possibility of lowering oxidative stress by using Ferulic acid, and at the same time anti-inflammatory properties of d'Arsonowal currents, it seems reasonable to apply both methods while performing single treatment. The application of Ferulic acid does not stand in counter-indication for emission of d'Arsonowal currents on the surface of the skin. It seems possible to demonstrate even higher effectiveness over the decrease of exanthema of both provenance in the process of Acne vulgaris in case of combining both kinds of treatments in the future. The extension of the research with another group of probands may bring crucial facts that can support the treatment of adult women suffering from adult acne.

\section{Declarations}

\section{Ethics Approval and Consent to Participate}

All procedures performed in studies involving human participants were in accordance with the ethical standards of the institutional and/or national research committee and with the 1964 Helsinki declaration and its later amendments or comparable ethical standards. All the study participants gave a written informed consent.

\section{Consent for Publication}

Not applicable, the manuscript doesn't contain any individual person's data.

\section{References}

1. O'Loughlin M (1964) Acne in the Adult Female. Australas J Dermatol $7(4): 218-222$.

2. Preneau S, Dreno B (2012) Female acne - A different subtype of teenager acne. J Eur Acad Dermatology Venereol 26(3): 277-282.

3. Dréno B, Layton A, Zouboulis CC, López-Estebaranz JL, ZalewskaJanowska A, et al. (2013) Adult female acne: A new paradigm. J Eur Acad Dermatology Venereol 27(9): 1063-1070.

4. Dréno B (2015) Treatment of adult female acne: a new challenge. J Eur Acad Dermatology Venereol 29(S5): 14-19.

5. Zeichner JA, Baldwin HE, Cook-Bolden FE, Eichenfield LF, FallonFriedlander S, et al. (2017) Emerging Issues in Adult Female Acne. J Clin Aesthetic Dermatology 10(1): 37-46.

6. Huang CJ, Zayas JF (1991) Phenolic Acid Contributions to Taste Characteristics of Corn Germ Protein Flour Products. J Food Science 56(5): 1308-1310.

7. Burns EM, Tober KL, Riggenbach JA, Kusewitt DF, Young GS, et al. (2013) Differential Effects of Topical Vitamin E and C E Ferulic ${ }^{\circledR}$ Treatments on Ultraviolet Light B-Induced Cutaneous Tumor Development in Skh-1 Mice. 8(5): e63809.

8. Roucayrol PE (1954) Bactericidal effect of d'Arsonval currents in the male and female genital tracts. J Radiol D'électrologie Arch D'électricité Médicale 35(5-6): 450-451.

9. Kasprzak W, Adamski Z, Białoszewski D, Bocian E, Tyski S (2012) Ozonot herapy and application of ozone as disinfectant. Advances in Microbiology 51(3): 177-184.

10. Szepietowski J, Kapińska-Mrowiecka M, Kaszuba A, Langner A, Placek W, et al. (2012) Trądzik zwyczajny: Patogeneza i leczenie. Konsensus Polskiego Towarzystwa Dermatologicznego. Dermatology Review 99(6): 649-673.

11. Dreno B, Thiboutot D, Layton AM, Berson D, Perez M, et al. (2015) Largescale international study enhances understanding of an emerging acne population: adult females on behalf of the Global Alliance to Improve Outcomes in Acne. JEADV 29: 1096-1106.

12. Sarici G, Cinar S, Armutcu F, Alt C, Koca R, et al. (2010) Oxidative stress in acne vulgaris. 24:763-767. 
13. Saija A, Tomaino A, Trombetta D, De Pasquale A, Uccella N, et al. (2000) In vitro and in vivo evaluation of caffeic and ferulic acids as topical photoprotective agents. Int J Pharm 199: 39-47.

14. Monti D, Tampucci S, Chetoni P, Burgalassi S, Saino V, et al. (2011) Permeation and Distribution of Ferulic Acid and Its alpha-Cyclodextrin Complex from Different Formulations in Hairless Rat Skin. AAPS PHARMSCITECH 12(2): 514-520.

15. Wu Y, Zheng X, Xu X-G, Li Y-H, Wang B, et al. (2013) Protective effects of a topical antioxidant complex containing vitamins $\mathrm{C}$ and $\mathrm{E}$ and ferulic acid against ultraviolet irradiation-induced photodamage in Chinese Women. J Drugs Dermatology 2(4): 464-468.

16. Kasprzak W, Mańkowska A, Fizjoterapia w (2010) kosmetologii i medycynie estetycznej. Wydawnictwo Lekarskie PZWL.

17. Valacchi G, Fortino V, Bocci V (2005) The dual action of ozone on the skin. Br J Dermatol 153(6): 1096-1100.

18. Lynch E, Swift EJ (2008) Evidence based efficacy of ozone for root canal irrigation. Journal of Esthetic and Restorative Dentistry 20(5): 287-293.
ISSN: 2574-1241

DOI: 10.26717/BJSTR.2018.07.001576

Izabela Zaleska. Biomed J Sci \& Tech Res

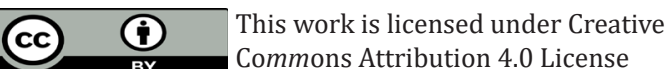

Submission Link: https://biomedres.us/submit-manuscript.php

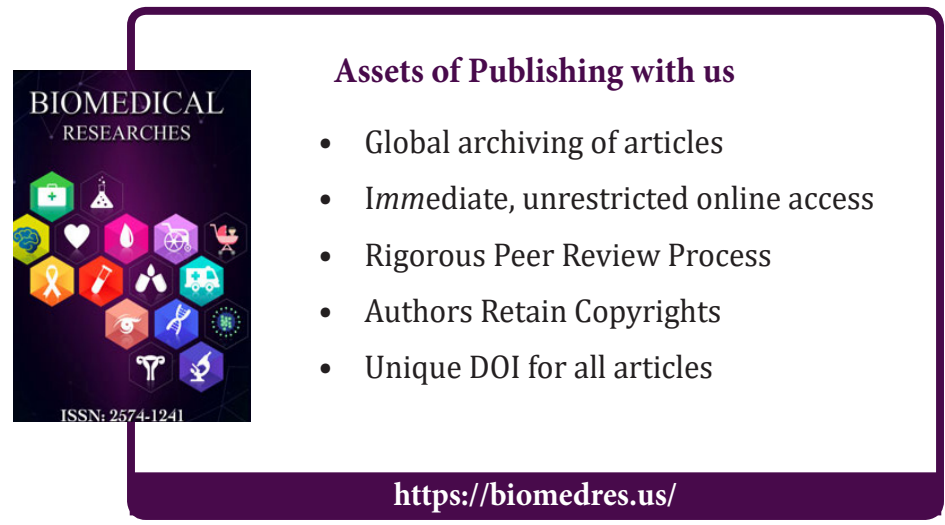

